INL/EXT-16-39465 Rev. 0

August 2016

\title{
Development and Validation of Accident Models for FeCrAl Cladding
}

K. A. Gamble

J. D. Hales

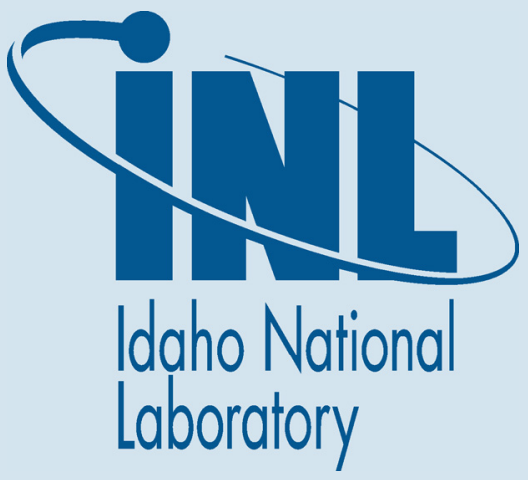




\section{NOTICE}

This information was prepared as an account of work sponsored by an agency of the U.S. Government. Neither the U.S. Government nor any agency thereof, nor any of their employees, makes any warranty, express or implied, or assumes any legal liability or responsibility for any third party's use, or the results of such use, of any information, apparatus, product, or process disclosed herein, or represents that its use by such third party would not infringe privately owned rights. The views expressed herein are not necessarily those of the U.S. Nuclear Regulatory Commission. 
INL/EXT-16-39465 Rev. 0

\title{
Development and Validation of Accident Models for FeCrAl Cladding
}

\author{
K. A. Gamble \\ J. D. Hales
}

August 2016

\begin{abstract}
Idaho National Laboratory
Fuel Modeling and Simulation Department

Idaho Falls, Idaho 83415
\end{abstract}

\author{
Prepared for the \\ U.S. Department of Energy \\ Office of Nuclear Energy \\ Under U.S. Department of Energy-Idaho Operations Office \\ Contract DE-AC07-99ID13727
}




\title{
Development and Validation of Accident Models for FeCrAl Cladding
}

\author{
K. A. Gamble and J. D. Hales \\ Fuels Modeling and Simulation \\ Idaho National Laboratory \\ P.O. Box 1625 \\ Idaho Falls, ID 83415-3840
}

August 1, 2016

\section{Introduction}

The purpose of this milestone report is to present the work completed in regards to material model development for FeCrAl cladding and highlight the results of applying these models to Loss of Coolant Accidents (LOCA) and Station Blackouts (SBO). With the limited experimental data available (essentially only the data used to create the models) true validation is not possible. In the absence of another alternative, qualitative comparisons during postulated accident scenarios between $\mathrm{FeCrAl}$ and Zircaloy-4 cladded rods have been completed demonstrating the superior performance of $\mathrm{FeCrAl}$.

\section{Material Model Development}

At the engineering scale, numerous new material models have been added to BISON for the laboratory optimized alloy known as C35M [1] under development at Oak Ridge National Laboratory (ORNL). In addition, a consistent set of material and behavioral models for $\mathrm{FeCrAl}$ have been decided upon for the qualitative rod comparisons shown in subsequent sections.

For the laboratory optimized $\mathrm{FeCrAl}$ alloy C35M developed at ORNL, models have been added for the mechanical and thermal properties as a function of temperature, thermal and irradiation creep, volumetric swelling and oxidation. The mechanical properties (Young's modulus and Poisson's ratio) were obtained from Thompson et al. [2]. Thermal properties, namely specific heat and thermal conductivity, for the commercial alloy Kanthal APMT are used [3]. The high temperature thermal creep model for MA956 developed by Seiler et al. [4] is used in the absence of other data. Representative models have been added for isotropic swelling and irradiation creep of FeCrAl claddings based upon engineering judgment. The oxidation model adopts the parabolic rate constant suggested by Pint et al. [5], and the conversion from mass gain to oxide thickness proposed by Jönsson et al. [6] is used. Recently, under the guidance of Kurt Terrani from ORNL it has been recommended that going forward the thermal creep model proposed by Saunders et al. [7] be scaled up by a factor of 1000 and used as the thermal creep correlation for C35M. A failure criteria has been added for $\mathrm{FeCrAl}$ alloys. This model is of particular importance during LOCA transients. As a starting point the failure model compares the hoop stress within the cladding and compares it with the ultimate tensile strength (UTS) of the alloy. The UTS varies as a function of temperature. An isotropic plasticity model has been added to BISON for $\mathrm{FeCrAl}$ alloys where the yield stress is a piecewise linear function of temperature. Both the UTS and yield stress values are obtained from Figure 10 in Yamamoto et al. [1]. 
Irradiation experiments are underway in both the Advanced Test Reactor at Idaho National Laboratory and the Halden Research Reactor in Norway for the C35M alloy. The material models in BISON will be updated and improved as the data becomes available for use.

\section{Verification}

Prior to validating a new material model it must be verified to known analytical or universally accepted textbook solutions. Verification essentially ensures that the correlation or model of interest has been coded correctly and that BISON is performing the mathematical calculation as expected. Verification is completed in BISON in part by ensuring regression tests are included with every new model added to the code. A detailed description of the verification procedure can be found in Hales et al. [8]. Every model for FeCrAl that has been added to BISON has been accompanied with a regression test.

\section{Simulation Model Development}

As mentioned previously, limited experimental data exists for the behavior of $\mathrm{FeCrAl}$ under irradiation. In addition, the data that is available was used to develop the material models in use. This has led to a lower length scale effort to develop more mechanistic (physics-based) models. While these models are under development important information can be garnered from simulations that compare the $\mathrm{FeCrAl}$ cladding response to the Zircaloy-4 response for representative cases. In this FY, investigations of two accident scenarios have been considered, namely LOCA and SBO. The details of the simulations and select results are presented in the following subsections.

\section{Application to a Loss of Coolant Accident}

The investigation of FeCrAl behavior during a LOCA scenario was completed by utilizing a modified version of the BISON 10 pellet example problem. Both a Zircaloy-4 and a FeCrAl cladded rodlet (with $\mathrm{UO}_{2}$ fuel) were subjected to the base irradiation power history shown in Figure 1 followed by a LOCA transient representative of a large break LOCA. To enable comparisons between the two systems, the initial rod diameter (cladding outer diameter) and fuelto-cladding gap are the same in both cases. The cladding thickness is varied depending on whether the material is Zircaloy- 4 or FeCrAl to simulate the thinner cladding required when $\mathrm{FeCrAl}$ is used to overcome the neutronic penalty introduced by the higher absorption cross-section. To compensate for the thinner cladding, the pellet diameter was increased for the $\mathrm{UO}_{2} / \mathrm{FeCrAl}$ system. A flat axial profile was assumed for this short rodlet. The transient begins at the conclusion of the base irradiation $(\approx 926.5$ days). To simulate the LOCA, the 1-D coolant channel model's inlet mass flux was dropped to $1 \mathrm{~kg} \mathrm{~m}^{-2} \mathrm{~s}^{-1}$ and the coolant pressure reduced to atmospheric over 10 seconds, thereby significantly reducing the cladding-to-coolant heat transfer coefficient. Meanwhile the power supplied to fuel is dropped to zero over two seconds where decay heat is turned on as a source term for the duration of the transient. The transient was terminated after $90 \mathrm{~s}$, and reflood was not modeled.

Selected comparative results during the LOCA transient are shown in Figure 2. The results shown are the fuel centerline temperature and the average cladding temperature. It is observed that the $\mathrm{UO}_{2} / \mathrm{FeCrAl}$ rodlet achieves lower temperatures than the $\mathrm{UO}_{2} /$ Zircaloy-4 rod. Determining the peak cladding temperature is an important criteria for Emergency Core Cooling Systems (ECCS) outlined in the NRC regulation 10 CFR 50.46. During the LOCA the average cladding temperature is close to the peak as the thermal conductivity is high through the cladding thickness essentially bringing the entire cladding to the coolant temperature. Improvements in areas of interest for the ECCS criteria indicate that based upon these preliminary calculations FeCrAl may have superior response to a LOCA transient than Zircaloy-4 cladding. Further investigation is required to determine definitively if $\mathrm{FeCrAl}$ is in fact superior to Zircaloy-4 under LOCA conditions.

\section{Application to a Station Blackout}

Investigation of the response of $\mathrm{FeCrAl}$ to postulated station blackout conditions was completed using the same 10 pellet rodlet in the LOCA case. The SBO scenario is modeled similarly to the LOCA except the coolant pressure remains at 15.5 MPa while the coolant flow is decreased to $100 \mathrm{~kg} \mathrm{~m}^{-2} \mathrm{~s}^{-1}$ to simulate the minimal flow provided by the backup 


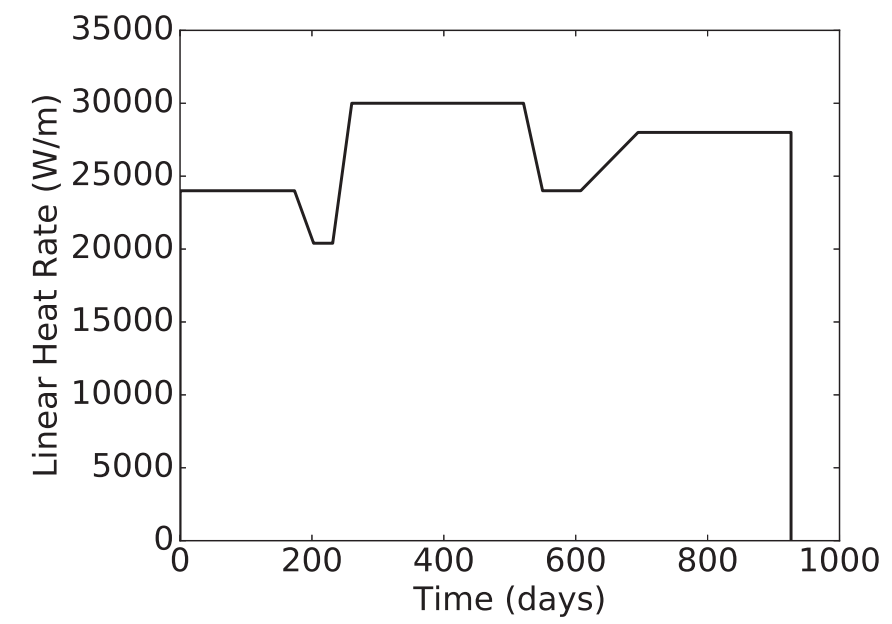

Figure 1: Representative base irradiation power history used for the LOCA transient.

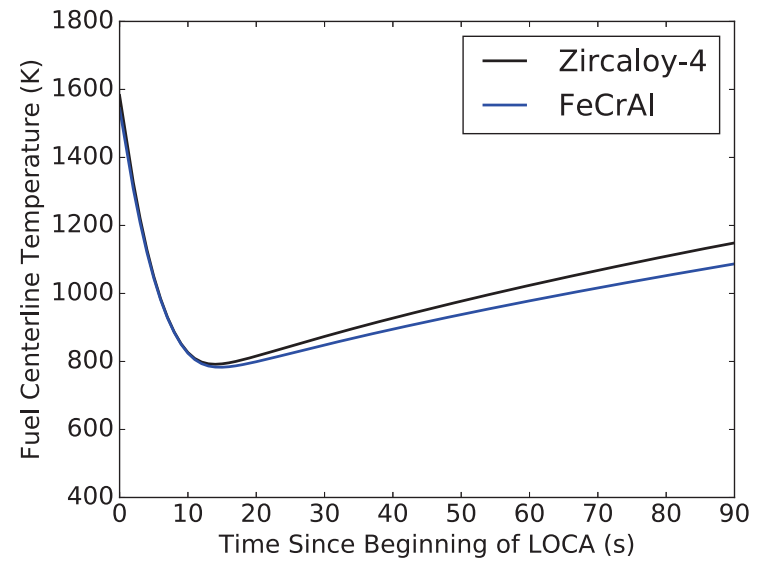

(a)

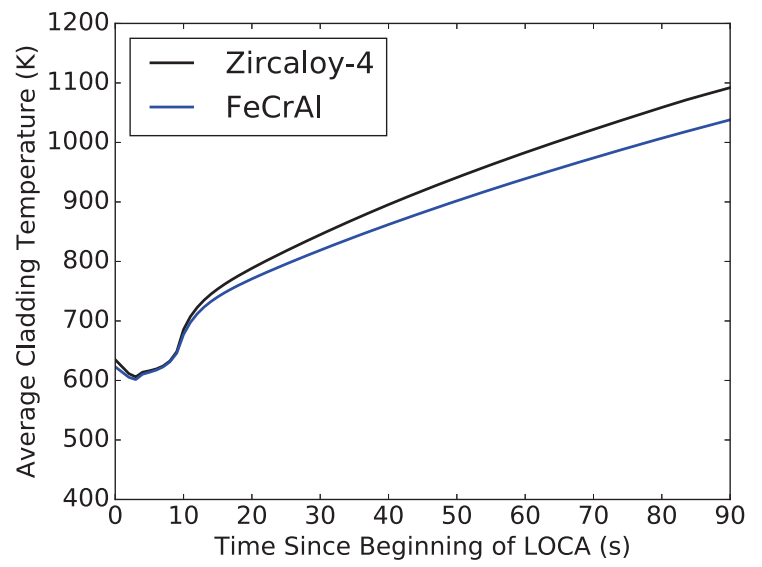

(b)

Figure 2: Temporal comparison of (a) centerline temperature and (b) cladding temperature during the LOCA transient for the Zircaloy-4 and FeCrAl cladded rods.

cooling system. As per the LOCA scenario the power is shut off over $2 \mathrm{~s}$ and decay heat is turned on as a heat source. Select comparative results for the SBO scenario are shown in Figure 3. The fuel centerline temperature and cladding hoop strain is presented. It is observed that the centerline temperature approaches the coolant inlet temperature rapidly. This can be attributed to the size of the rodlet considered. The coolant channel model takes the bottom of the rodlet as the inlet and because the rodlet is only $107.2 \mathrm{~mm}$ long it can still be cooled quickly with minimal coolant flow. Subsequently, because the fuel and cladding temperatures remain low, the stress induced in the cladding is minimal. Thus, simulations of full-length fuel rods are required to provide conclusive qualitative comparisons of the two systems during a station blackout event. It should be noted that the reduced flow does decrease the rate of cooling from full power.

\section{Publications}

Throughout this FY, three conference publications have been produced on this work. These publications are a full paper presented at the Enlarged Halden Programme Group (EHPG) meeting in Norway (May 8-13, 2016), a full paper accepted to the TopFuel 2016 conference in Boise (September 11-16, 2016), and an ANS Transactions summary presented as a poster at the ANS Annual meeting in New Orleans (June 12-16, 2016). The EHPG paper and ANS 


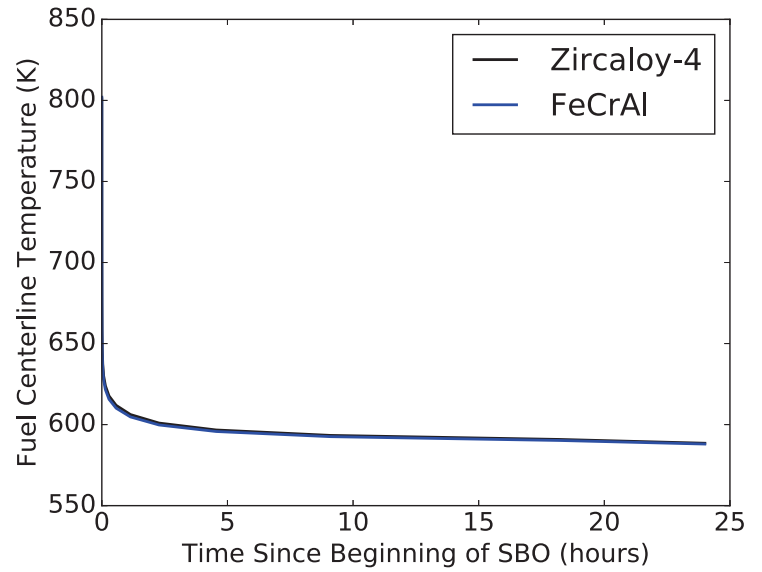

(a)

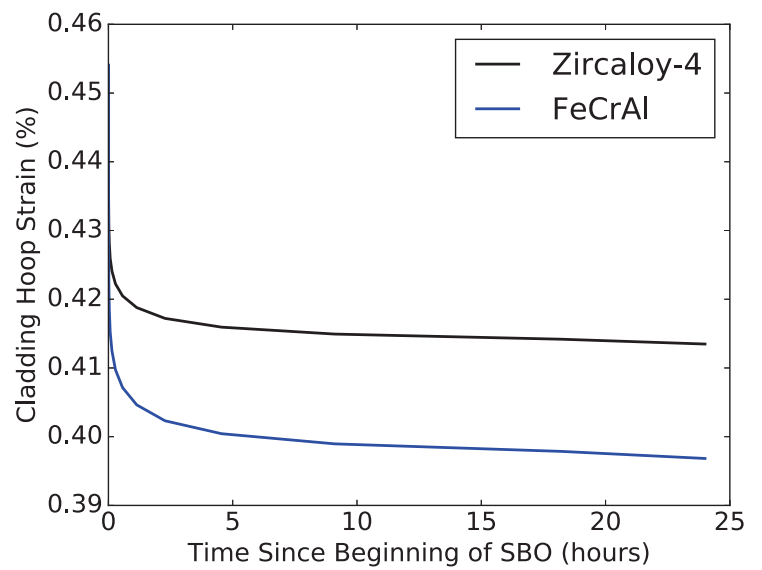

(b)

Figure 3: Temporal comparison of (a) centerline temperature and (b) cladding hoop strain during the SBO transient for the Zircaloy-4 and FeCrAl cladded rods.

summary focused normal operating conditions and preliminary LOCA simulations. Both comparative and sensitivity analyses were completed. The TopFuel paper extends the LOCA analysis to longer exposure times, higher burnups and investigates a modified set of sensitive input parameters. In addition, the TopFuel paper covers the preliminary investigations of station blackouts. A journal paper is currently in preparation.

\section{Conclusion}

This report documents recent work in the development and validation of accident capabilities for FeCrAl cladding including:

- Standard material model options have been chosen for FeCrAl under accident conditions.

- Verification of the material models have been completed.

- Preliminary qualitative comparisons between FeCrAl and Zircaloy-4 cladded rods indicates superior performance of $\mathrm{FeCrAl}$ under accident conditions.

Although significant insight into the behavior of $\mathrm{FeCrAl}$ fuel under accident conditions has been completed, development and testing of accident models is far from complete. As additional experimental data is obtained and new lower length scale models are developed, new and improved material models will be added to the BISON fuel performance code. Future goals include:

- Improve the thermal and irradiation creep models for $\mathrm{FeCrAl}$ as experimental data becomes available.

- Improve the isotropic volumetric swelling model for $\mathrm{FeCrAl}$ as data becomes available.

- Introduce the lower length scale VPSC model under development at LANL into BISON.

- Apply the newly introduced failure criteria model to RIA, LOCA, and SBO conditions.

- Investigate the accident response of FeCrAl on full length rods for RIA, LOCA and SBO conditions.

\section{References}

[1] Y. Yamamoto, B.A. Pint, K.A. Terrani, K.G. Field, Y. Yang, and L.L. Snead. Development and property evaluation of nuclear grade wrought $\mathrm{FeCrAl}$ fuel cladding for light water reactors. Journal of Nuclear Materials, 467:703$716,2015$. 
[2] Z. T. Thompson, K. A. Terrani, and Y. Yamamoto. Elastic Modulus Measurement of ORNL ATF FeCrAl Alloys. Technical Report ORNL/TM-2015/632, Oak Ridge National Laboratory, October 2015.

[3] Kanthal APMT Material Database. http://kanthal.com/en/products/material-datasheets/tube/kanthal-apmt/.

[4] P. Seiler, M. Bäker, and J. Rösler. Variation of creep properties and interfacial roughness in thermal barrier coating systems. Advanced Ceramic Coatings and Materials for Extreme Environments, 32:129-136, 2011.

[5] B.A. Pint, K.A. Terrani, Y. Yamamoto, and L.L. Snead. Material Selection for Accident Tolerant Fuel Cladding. Metallurgical and Materials Transactions E, 2E:190-196, 2015.

[6] Bo Jönsson, Qin Lu, and Dilip Chandrasekaran. Oxidation and Creep Limited Lifetime of Kanthal APMT, a Dispersion Strengthened FeCrAlMo Alloy Designed for Strength and Oxidation Resistance at High Temperatures. Oxidation of Metals, 79:29-39, 2013.

[7] S. R. J. Saunders, H. E. Evans, M. Li, D. D. Gohil, and S. Osgerby. Oxidation growth stresses in an alumina-forming ferritic steel measured by creep deflection. Oxidation of Metals, 48:189-200, 1997.

[8] J. D. Hales, S. R. Novascone, B. W. Spencer, R. L. Williamson, G. Pastore, and D. M. Perez. Verification of the BISON fuel performance code. Ann. Nuclear Energy, 71:81-90, 2014. 